\title{
Effects of Cryoprotectants and Post-storage Priming on Seed Germination of Sugi (Cryptomeria japonica D. Don)
}

\author{
By Du Hyun Kim${ }^{1)}$, Sim Hee HaN ${ }^{1)}$, JA Jung Kü2) and Kab Yeon LeE ${ }^{1)}$
}

Department of Forest Genetic Resources, Korea Forest Research Institute, Suwon, 441-350, Korea

(Received $22^{\text {th }}$ February 2008)

\begin{abstract}
Among the ex situ methods for the preservation of forest tree germplasm, conventional seed banking is considered the most efficient method for the majority of species whilst cryopreservation has an important role in long-term conservation. The influence of cryoprotectants prior to liquid nitrogen (LN) storage and osmoconditioning priming treatments with polyethylene glycol (PEG) after LN storage were evaluated for germination (\%), germination value $(\mathrm{GV})$ and mean germination time (MGT) in seeds of Cryptomeria japonica. Sugi seeds were treated with two cryoprotectants (DMSO and PVS2) before immersion into LN and stored for three days. Although the $C$. japonica seeds survived liquid nitrogen treatment, their viability was reduced from $25 \%$ of intact seeds to $17 \%$ in LN. The seeds treated with $35 \%$ DMSO showed higher germination (28\%) as compared with seeds directly-immersed in LN without cryoprotectant treatment. In contrast, PVS2 pretreated seeds decreased germination (13\%). Two concentrations of PEG priming treatments were carried out. Osmoconditioning treatment in $-0.4 \mathrm{MPa}$ PEG solution after removal from LN enhanced the subsequent germination percentage and decreased MGT. PEG treatments at both -0.4 and $-1.2 \mathrm{MPa}$ to PVS2 pretreated seeds before cryopreservation partially alleviated the negative effect of PVS2. DMSO pretreated seeds immersed into $\mathrm{LN}$ and treated with $-0.4 \mathrm{MPa}$ PEG maintained the $28 \%$ of germination obtained in the control conditions and reduced the mean germination time (MGT). It can therefore be summarized that pretreatment with $35 \%$ DMSO was suitable for the cryopreservation of $C$. japonica seeds whilst the PEG priming treatment circumvented imbibitional damage after LN exposure.
\end{abstract}

Key words: Cryptomeria japonica, seed storage, liquid nitrogen, cryoprotectant, DMSO, PVS2, priming, cryopreservation, ex situ conservation.

\section{Introduction}

Sugi, Cryptomeria japonica D. Don (Taxodiaceae), has long been valued for the beauty of both the tree and wood and is planted as an ornamental in warm and cool temperate climates. Cryptomeria japonica usually exhibits poor to very poor seed germination by showing only about $30 \%$ in standard germination tests (PARRY, 1956; KFRI, 2004). SAITO and TAIRA (2005) reported that the average germination percentage of seeds of 55

\footnotetext{
1) Author for corresponding: Du Hyun KIM. Telephone: 82-31-2901158, Fax: 82-31-290-1040. E-Mail: dhkim@forest.go.kr

2) Department of Forest Resource Conservation, National Arboretum. Gyeonggi-do 487-821, Korea.
}

Japanese cedar lines was $46 \%$, ranging from 10 to $72 \%$ in Japan. Significant reduction in the viability of seeds of $C$. japonica has been frequently encountered even after relatively short storage durations of 2 to 3 years at room temperature. Vegetative propagation is therefore routinely practiced in commercial nurseries.

As a result of progressive forest decline, the development of conservation strategies to avoid the loss of genetic viability and diversity is required. Among the $e x$ situ methods for the preservation of forest tree germplasm, seed banking is considered the most efficient and economic method for the conservation of genetic resources. It is estimated that 6 million samples of plant genetic resources are held in national, regional, international and private gene bank collections around the world (IPGRI, 2004; PANIS and LAMBARDI, 2005).

However, for some forest trees, a rapid decrease in seed viability necessitates the development of improved storage methods. The development of comparatively simple cryostorage protocols has allowed seeds from over 155 agricultural species to be stored at low cost, without obvious problems of seed aging, genetic variation and predation common to many conventional seed storage methods (STANDWOOD, 1985). In this regard, seeds from at least $40 \%$ of the rare and endangered species in Western Australia could be maintained through the use of cryopreservation techniques (Touchell and Dixon, 1993). Many woody species have non-orthodox seeds that cannot be safely preserved in seed banks. Hence, the cryopreservation of such germplasm can be an important complementary approach to the safe guarding of woody plant biodiversity, assuming that the development of a low-input and widely-applicable technology is pursued. At cryogenic temperatures, the rate of chemical and biophysical reactions is so slow that the biological growth and development of the ultra-frozen organ/tissue are hampered, while, if a proper technique for ultra-rapid freezing is applied, cell survival is not affected. There is evidence that cryopreservation in liquid nitrogen improves seed survival (CHEN et al., 2007; PANIS and LAMBARDI, 2005; STANWOOD and SowA, 1995).

In many cases, providing that the water content is kept within a reasonable range, desiccation-tolerant seeds can commonly be directly immersed into liquid nitrogen without a decrease in germination (STANWOOD, 1985). The cryopreservation technique was first applied to plant tissues in the $1970 \mathrm{~s}$; however, it has not been utilized on a wide scale due to the high cost of cryofreezers. New cryogenic techniques are now available, 
aiming at the direct immersion in liquid nitrogen ("onestep freezing"), without resorting to expensive apparatus for slow cooling and with a considerable simplification of procedures. Problems of devitrification are mostly avoided in dry seeds where glass transition temperatures are greater than the melting temperature of ice (LAMBARDI et al., 2005).

First reports on the use of vitrification solutions with plant tissues appeared in 1989 (LANGIS et al., 1989; URAGAMI et al., 1989). The technique relies on treatment of explants with a concentrated vitrification solution for variable periods (from 15 minutes up to 2 hours), followed by a direct plunge into liquid nitrogen ("vitrification/one-step freezing"). This apparently results in both intra- and extra-cellular vitrification (PANIS and LAMBARDI, 2005). The vitrification solution consists of a concentrated mixture of penetrating and non-penetrating cryoprotectant substances. The most commonly applied solution is plant vitrification solution No. 2 (PVS2). Commonly used penetrating cryoprotective agents are dimethyl sulphoxide (DMSO) and glycerol. For many applications, DMSO is preferred because of its extremely rapid penetration into the cells. Where DMSO toxicity is a problem, gycerol or amino acids are often applied. PVS2 solution has been successfully used for the cryopreservation of shoot tips from several economicallyimportant hardwood species (e.g. Malus, Pyrus, Prunus, and Populus spp., Vitis spp.). Cryopreservation has also been applied successfully for softwood trees (e.g. Picea, Pinus, Larix, Abies and Pseudotsuga) (PANIS and LAMBARDI, 2005). Generally, the various effects of storage in liquid nitrogen, cryoprotectant concentration, cooling rate, sample water content, and the interaction of stratification or scarification (for seeds) with cryopreservation have been studied.

Water can also influence the survival rate of orthodox seeds during imbibition: the rapid uptake of water by dry seeds can result in imbibition injury. Seeds are more likely to be damaged by the rapid decreases in their initial water content (ELLIS, 1998) that also could be an important procedure for seed cryopreservation and lower temperatures of imbibition water (HoNG and ELLIS, 1996). Imbibition injury can be minimized by conditioning (humidifying) the seeds in a moist atmosphere (close to $100 \% \mathrm{RH}$ ) in order to raise seed water contents to $16-18 \%$ before the seeds are set to germinate in contact with liquid water (ELLIS et al., 1985). It is suggested that seeds with $8 \%$ water content or below, irrespective of species, should routinely be humidified before germination. Seed priming, which aims to promote faster, more uniform seedling emergence (CORBINEAU and Côme, 2006), may also increase longevity in certain species (PROBERT et al., 1991) and can also reduce desiccation tolerance when seeds are dried to low water contents (CORBINEAU and Côme, 2006). The goal of gene banking is essentially the maintenance of high seed viability in a very wide range of species for much longer periods. The loss of seed vigour may be reversible to some extent and can be restored by priming (SIVRITEPE and Dourado, 1995; Oluoch and Welbaum, 1996).

We, therefore, investigated the effects of storage in liquid nitrogen $\left(-196^{\circ} \mathrm{C}\right)$, the effects of cryoprotectants, and osmoconditioning priming treatment with polyethylene glycol solution after LN immersion in this study. Our aim was to develop efficient methods for the longterm ex situ conservation of $C$. japonica seeds, which exhibits low germination and short storage characteristics.

\section{Material and Methods}

\section{Seed Sources and Handling}

Seeds were collected in 2005 from the seed orchard in Jeju Island operated by the Forest Research Institute, Korea. The seeds were extracted, cleaned, and stored in darkness and at $-20^{\circ} \mathrm{C}$ until use in 2007. Before the storage, damaged and insect infected seeds were discarded, and the empty seeds were eliminated using the water floating method.

\section{Cryopreservation}

The seeds with an average water content of $7.83 \%$ were sealed in polypropylene cryovials of $10-\mathrm{ml}$ capacity and frozen by direct plunging in liquid nitrogen $\left(-196^{\circ} \mathrm{C}\right)$. After 3 days of cryopreservation the cryovials were rapidly thawed in a water bath at $37^{\circ} \mathrm{C}$ for $15 \mathrm{~min}$ and subsequently the seeds were used for germination test or priming treatments.

\section{Cryoprotectant treatment}

For cryoprotectant treatment, seeds were immersed in cryoprotectant solution for $2 \mathrm{hrs}$ at $25^{\circ} \mathrm{C}$ before plunging into the liquid nitrogen. The cryoprotectant solutions were

(1) PVS2: DMSO 15\% (w/v), ethylene glycol 15\% (w/v), glycerol $30 \%(\mathrm{w} / \mathrm{v})$ (SAKAI et al., 1990) and

\section{(2) $35 \%$ DMSO (dimethyl sulfoxide, $\mathrm{Me}_{2} \mathrm{SO}$ ).}

Intact (untreated) seeds that had no treatment with LN or cryoprotectant were compared with treated seeds. Control seeds in a cryovial were directly plunged into the LN without any pretreatment of cryoprotectant solution.

\section{PEG priming treatment}

Seeds that were thawed after cryopreservation were primed using osmotic solutions at -0.4 and $-1.2 \mathrm{MPa}$ for three days in darkness at $15^{\circ} \mathrm{C}$ using polyethylene glycol (PEG 8000). The water potential of the PEG solution for osmopriming treatments was determined using the calculation method of MICHEL (1983).

\section{Germination analysis}

Germination tests were performed on two layers of filter paper saturated with water in 9-cm-diameter glass petri dishes. Four 50-seed replicates for each treatment were used. Experiments were carried out in a temperature-controlled growth chamber at $20^{\circ} \mathrm{C}$ under constant light. Germination counts were performed daily for 28 days and germination was considered to have occurred if the radicle protruded $2 \mathrm{~mm}$ or longer from the seed coat according to the ISTA rules (ISTA, 1999). The total germination percentage was expressed as the average of the four replicates. The parameters of germination 
speed, mean germination time (MGT) and germination value $(\mathrm{GV})$, were also calculated for supplementary explanations. MGT was calculated as follows: $\mathrm{MGT}=\sum \mathrm{n}_{\mathrm{i}} \mathrm{d}_{\mathrm{i}} / \mathrm{n}$, where $\mathrm{n}$ is the total number of germinated seeds during the germination test, $n_{i}$ is the number of germinated seeds on day $d_{i}$ and $i$ is the number of days during the germination period (between 0 and 28 days) (Yousheng and SzIKLAI, 1985). The germination value was calculated using the equation $\mathrm{GV}=\mathrm{PV} \times \mathrm{MDG}$ (CzABATOR, 1962), where GV is the germination value, $\mathrm{PV}$ is the peak value. Peak value was calculated as the quotient of the highest value of the cumulative germination percentage, divided by the number of days from the beginning of the test, and MDG is the average daily germination. Duncan's multiple range tests (DMRT) at $p=0.05$ were further used for the comparison of the means using the SAS statistical program (SAS Institute Inc., 1996).

\section{Results}

The effect of cryoprotectant pretreatment on sugi seeds immediately before the plunging into liquid nitrogen (LN) is shown in Table 1.

Intact seeds showed an average germination percentage of $25 \%$, MGT of 15.14 days, and GV of 1.05 . Those seeds directly plunged into LN for cryopreservation had a $17.0 \%$ germination thus showing a significant reduction in germination even so the seeds still maintained some germinability. Treatment with cryoprotectants influenced sugi seed germination. DMSO was highly effective in alleviating the adverse effect of cryopreservation by showing $28.0 \%$ germination whereas PVS2 failed to show promotive effect. Even though DMSO treatment showed lowest MGT (12.2 days) and highest GV (3.39) among treatments, it was not statistically significantly different.

Table 1. - Effects of cryoprotectant pretreatment on germination percentage, mean germination time (MGT), and germination value (GV) of Cryptomeria japonica seeds.

\begin{tabular}{lcccc}
\hline Treatment & \multicolumn{2}{c}{ Germination (\%) } & MGT (day) & GV \\
\hline Intact (Untreated) & $25.0 \pm 3.83 \mathrm{a}^{\mathrm{z}}$ & $15.14 \pm 2.44 \mathrm{~ns}^{\mathrm{y}}$ & $1.05 \pm 0.50 \mathrm{~ns}$ \\
Control (LN $\mathrm{LN}^{x}$ only) & $17.0 \pm 2.03 \mathrm{~b}$ & $13.38 \pm 2.41$ & $0.55 \pm 0.16$ \\
PVS2 + LN & $13.0 \pm 3.83 \mathrm{~b}$ & $15.12 \pm 4.59$ & $0.39 \pm 0.44$ \\
DMSO + LN & $28.0 \pm 2.86 \mathrm{a}$ & $12.20 \pm 1.49$ & $3.39 \pm 2.60$ \\
\hline
\end{tabular}

All the values are means of four replicates \pm standard deviation (SD); Intact (untreated) seeds had no treatment with LN; Control seeds were directly plunged into the LN without any pretreatment of cryoprotectant solution.

${ }^{z}$ Values in the same column with different letters are significantly different from each other at $p=0.05$, Duncan's Multiple Range test.

${ }^{\mathrm{y}}$ n.s.: not significantly different.

${ }^{\mathrm{x}}$ Preserved in liquid nitrogen (LN).

Table 2. - Effects of PEG priming treatment after cryopreservation on seed germination of Cryptomeria japonica.

\begin{tabular}{lrrrrr}
\hline Treatment & Germination (\%) & MGT (day) & GV \\
\hline Intact (Untreated) & $25.0 \pm 3.83$ & $\mathrm{a}^{\mathrm{z}}$ & $15.14 \pm 2.44$ & $\mathrm{a}$ & $1.05 \pm 0.50 \mathrm{~ns}^{\mathrm{y}}$ \\
Control (LN $\mathrm{LN}^{x}$ only) & $17.0 \pm 2.03$ & $\mathrm{~b}$ & $13.38 \pm 2.41$ & $\mathrm{ab}$ & $0.55 \pm 0.16$ \\
$\mathrm{LN}+-0.4 \mathrm{MPa}$ PEG & $25.0 \pm 3.57$ & $\mathrm{a}$ & $10.21 \pm 1.22$ & $\mathrm{~b}$ & $1.93 \pm 2.15$ \\
$\mathrm{LN}+-1.2 \mathrm{MPa}$ PEG & $15.0 \pm 2.01$ & $\mathrm{~b}$ & $9.29 \pm 2.20$ & $\mathrm{~b}$ & $0.60 \pm 0.06$ \\
\hline
\end{tabular}

All the values are means of four replicates \pm standard deviation (SD); Intact (untreated) seeds had no treatment with LN; Control seeds were directly plunged into the LN without any pretreatment of cryoprotectant solution.

${ }^{\mathrm{z}}$ Values in the same column with different letters are significantly different from each other at $p=0.05$, Duncan's Multiple Range test.

${ }^{\mathrm{y}}$ n.s.: not significantly different.

${ }^{x}$ Preserved in liquid nitrogen (LN). 
Table 3. - Effect of combined treatments of PVS2 cryoprotectant and PEG priming on germination of Cryptomeria japonica seed.

\begin{tabular}{|c|c|c|c|}
\hline Treatment & Germination (\%) & MGT (day) & GV \\
\hline Intact (Untreated) & $25.0 \pm 3.83 \mathrm{a}^{\mathrm{z}}$ & $15.14 \pm 2.44 \mathrm{~ns}^{\mathrm{y}}$ & $1.05 \pm 0.50 \mathrm{~ns}$ \\
\hline Control (PVS $2+\mathrm{LN}^{x}$ only) & $13.0 \pm 3.83$ & $15.13 \pm 4.59$ & $0.39 \pm 0.44$ \\
\hline PVS2+LN +-0.4MPa PEG & $22.0 \pm 2.33$ & $12.81 \pm 4.18$ & $1.14 \pm 0.87$ \\
\hline PVS2+LN +-1.2MPa PEG & $21.0 \pm 2.00$ & $11.48 \pm 2.91$ & $1.05 \pm 0.61$ \\
\hline
\end{tabular}

All the values are means of four replicates \pm standard deviation (SD); Intact (untreated) seeds had no treatment with LN; Control seeds were directly plunged into the LN without any pretreatment of cryoprotectant solution.

${ }^{z}$ Values in the same column with different letters are significantly different from each other at $\mathrm{p}=0.05$, Duncan's Multiple Range test.

${ }^{\mathrm{y}}$ n.s.: not significantly different.

${ }^{\mathrm{x}}$ Preserved in liquid nitrogen (LN).

The effects of PEG priming treatment of sugi seeds that had been preserved in LN are shown in Table 2.

Priming with -0.4 $\mathrm{MPa}$ polyethylene glycol 8000 (PEG) was effective in restoring the germination reduction caused by cryopreservation $25 \%$ as it was obtained in the control conditions. However, priming with -1.2 $\mathrm{MPa}$ PEG failed to show such an effect (15\%). On the contrary, the LN treatment adversely affected seed germination by showing significantly lower germination. MGT was significantly shortened by $-0.4 \mathrm{MPa}$ PEG priming (10.21 days) as compared to the non-primed seeds (13.38 days) or the intact seeds (15.14 days). GV of -0.4 MPa PEG priming treated seeds showed the highest value among the treatments, but it was not significantly different.

Effects of seed priming were also tested using the seeds exhibiting low germination due to the cryopreservation with PVS2 protectant treatment (Table 3).
Priming treatments, $-0.4 \mathrm{MPa}$ and $-1.2 \mathrm{MPa}$ PEG, were effective in restoring the germination percentages to levels comparable with that of intact seeds. Even though both PEG priming treatments resulted low MGT and high GV mean values, the treatments were not statistically different at the $\mathrm{p}=0.05$ level in MGT and GV.

PEG priming treatment was also tested on seeds pretreated with the cryoprotectant DMSO (Table 4).

The germination percentages after PEG priming of the seeds did not show statistically significant differences compared to controls. On the contrary, a significant reduction in germination was observed, with -1.2 MPa PEG. It is worthwhile to note that MGT was significantly shortened by $-0.4 \mathrm{MPa}$ PEG priming (7.62 days) compared to the non-primed seeds (12.30 days) or the intact seeds (15.14 days). Although mean values of GV showed high differences, significant differences between treatments were not found in all priming treatments.

Table 4. - Effect of combined treatments of DMSO cryoprotectant and PEG priming on germination of Cryptomeria japonica seeds.

\begin{tabular}{|c|c|c|c|}
\hline Treatment & Germination (\%) & MGT (day) & GV \\
\hline Intact (Untreated) & $25.0 \pm 3.83 \mathrm{a}^{z}$ & $15.14 \pm 2.44 \mathrm{a}$ & $1.05 \pm 0.50 \mathrm{~ns}^{\mathrm{y}}$ \\
\hline Control (DMSO $+\mathrm{LN}^{z}$ only) & $28.0 \pm 2.86 \quad \mathrm{a}$ & $12.30 \pm 1.49 \mathrm{~b}$ & $3.39 \pm 2.60$ \\
\hline $\mathrm{DMSO}+\mathrm{LN}^{z}+-0.4 \mathrm{MPa}$ PEG & $28.0 \pm 2.86$ & $7.62 \pm 0.51 \mathrm{c}$ & $3.06 \pm 2.19$ \\
\hline $\mathrm{DMSO}+\mathrm{LN}^{z}+-1.2 \mathrm{MPa}$ PEG & $19.0 \pm 3.87$ & $12.03 \pm 2.44 \mathrm{~b}$ & $0.88 \pm 0.61$ \\
\hline
\end{tabular}

All the values are means of four replicates \pm standard deviation (SD); Intact (untreated) seeds had no treatment with LN; Control seeds were directly plunged into the LN without any pretreatment of cryoprotectant solution.

${ }^{z}$ Values in the same column with different letters are significantly different from each other at $\mathrm{p}=0.05$, Duncan's Multiple Range test.

${ }^{\mathrm{y}}$ n.s.: not significantly different.

${ }^{\mathrm{x}}$ Preserved in liquid nitrogen (LN). 


\section{Discussion}

\section{Effects of cryoprotectants}

Cryogenic storage has been successfully carried out in many orthodox seed species including several pine species (AHUJA, 1986; PITA et al., 1997; PANIS and LAMBARDI, 2005). However, in this research survival rates were decreased to $68 \%$ of that of non-immersed seed by LN immersion. Similarly cryopreservation negatively affected Pinus pinea seed viability which fell to $24 \%$ of the control with the seed oil content being proposed as an important factor (PITA et al., 1998). In this regard, VERTUCCI (1989) reported sensitivity to cryopreservation in Pisum sativum, Helianthus annuus and Glycine max, which all seeds with high lipid contents. It has been hypothesized that the interaction between the lipid and water during freezing is responsible of the formation of ice crystals that were large enough to cause lethal damage (Hor et al., 2005). The chemical composition of the seed, mainly oil seed content, might explain the effect of cryopreservation in this $C$. japonica, although no loss of viability has been found in other species with high lipid contents such as Dodonaea, Templotnia, and Allocauarina after cryopreservation (TOUCHELL and DiXON, 1994).

PVS2 is known to have protective effects for embryo, axis or shoot tips in Citrus, Coffea, Populus, and Quercus (LAMBARDI et al., 2005; PANIS and LAMBARDI, 2005), but only DMSO was effective in our studies with sugi seeds thus suggesting the existence of some sensitive relationship between the composition of cryoprotectants and seed sources as suggested by TOUCHELL and DIXON (1993). DMSO's permeability is not markedly affected by low temperature and is, therefore, the most widely used penetrating cryoprotectant. Propylene glycol decreases the polarity of the aqueous phase and changes the partition of hydrophobic molecules between the cell membrane and the external phase, causing dehydration of the phospholipid bilayer and possible membrane damage. Cryoprotectants can suppress most cryoinjuries but, when used at too higher concentrations, most of them become toxic to biological material (LEUNG, 1991). According to Touchell and DixON (1993) $15 \%$ and $35 \%$ DMSO were effective in seeds of 16 native Western Australian species. Result of the present study also supports the notion that cryoprotectants concentration and exposure time varies depending on the seed morphology and structure. In the present research $35 \%$ DMSO was effective in increasing survival rate after $\mathrm{LN}$ exposure whilst a 2 hrs exposure to PVS2 caused a chronic effect on C. japonica seed. GV was also highest in sugi seeds preserved in LN after being pretreated with DMSO, although the actual germination percentages were generally lower as pointed out in several previous reports (PARRY, 1956; KFRI, 2004; SAITO and TAIRA, 2005) even though we used freshly harvested and uniform seeds for the germination test. Little or no reports are available for the causes of low germination in sugi and further studies are needed in this regard.

\section{Effects of post-storage priming}

Controlled post-thaw rehydration of seeds, i.e., 6-week osmoconditioning treatment in $-1.25 \mathrm{MPa}$ polyethylene glycol, dramatically increased viability of frozen seeds. However, this effect was variable within the accessions studied and independent of seed viability after desiccation or desiccation and LN exposure (VASQUEZ et al., 2005). Dusser et al. (2003) suggested that the high sensitivity of coffee seeds to LN exposure was not directly associated with the occurrence of an oxidative stress during post-thaw rehydration. However, desiccation tolerance of coffee seed increase with, by increasing order, seed osmoconditioning that slow down the rate of water uptake, pre-heating temperature $\left(25\right.$ or $\left.37^{\circ} \mathrm{C}\right)$ and prehumidifying duration ( 24 or $48 \mathrm{~h}$ ) prior to their culture under germination conditions. This rehydration procedure also dramatically increased seed viability after LN exposure. These results support the hypothesis that imbibitional membrane damage is involved in the sensitivity of seeds to LN exposure as observed with coffee seeds. The rapid uptake of water by dry seeds can result in imbibition injury (HONG and ELLIS, 1996). The effect on seed viability of different rehydration procedures previously identified to reduce membrane imbibition injury by LN exposure was presently tested. In this research priming treatment with $-0.4 \mathrm{MPa}$ PEG for 3 days adjusted seed water content to levels suitable to avoid imbibition injury whilst the $-1.2 \mathrm{MPa}$ PEG 3 day treatment was insufficient to reach proper rehydration levels. This effect corroborates previous reports that high PEG concentration can be detrimental to seed germination (STOFELla et al., 1992; KIM et al., 2006).

Since we do not know about the factor(s) influencing the shift in germination behavior, either promoting or inhibiting, further research should be focused on the causes or physiological changes during the germination and priming processes. Even though only a limited number of cryoprotectants and priming treatments were tested in our study, systematic research should be conducted to screen various treatments, time and duration of each treatment and the precise handling of the seeds throughout the experimental period in order to maximize the seed germination of $C$. japonica.

In theory, germplasm cryopreservation can be considered unlimited in terms of time (LAMBARDI et al., 2005). However, recently it has been reported that cryogenic temperatures may not be sufficient to stop deterioration especially if the initial stages of aging were allowed to progress at higher storage temperatures. In spite of the obvious advantage of ultra-cold storage in seeds much of the underlying biological understanding is still not clear (DiCKIES et al., 1990; ElLIS, 1998; WALTERS et al., 2004). Further detailed research on various parameters that influence cryo-behavior, especially lipid content, membrane composition, cryoprotective proteins and unfrozen water content in this species must be evaluated.

Pretreatment of $C$. japonica with DMSO as a pretreatment prior to immersion into $\mathrm{LN}$ can be practiced for long term ex situ conservation of this forestry species. It provides an alternative method that extends sugi seed viability compared with those seeds that are stored at room temperature, which last about 2-3 years. Additionally, a priming treatment with a $-0.4 \mathrm{Mpa}$ PEG solution for post-thaw recovery improves the viability of 
seeds. The study proved that the "vitrification/one-step freezing" technique using DMSO and priming treatment is an effective method for the ex situ germplasm conservation of Cryptomeria japonica.

\section{Acknowledgements}

This study was funded by the Korea Forest Research Institute. We thank J. S. KIM for providing seed material.

\section{References}

AHUJA, M. R. (1986): Short Note: storage of forest tree germplasm in liquid nitrogen $\left(-196^{\circ} \mathrm{C}\right)$. Silvae Genetica 35: 5-6.

Chen, S. Y., S. R. Kuo, C. T. Chien, J. M. Baskin and C. C. BASKIN (2007): Germination, storage behaviour and cryopreservation of seeds of Champereia manillana (Opiliaceae) and Schefflera octophylla (Araliaceae). Seed Science and Technology. 35: 154-164.

Corbineau, F. and D. Côme (2006): Priming: a technique for improving seed quality. Seed Testing International 132: 38-40.

CzABATOR, F. J. (1962): Germination value: an index combining speed and completeness of pine seed germination. Forest Science 8: 386-396.

Dickies, J. B., R. H. Ellis, H. L. KraAk, K. Ryder and P. B. Tompsett (1990): Temperature and seed storage longevity. Ann. Bot. 65: 197-204.

Dusser, S., N. Chabrillange, J. L. Montillet, J. P. Agnel, F. Engelmann and M. Noirot (2003): Basis of coffee seed sensitivity to liquid nitrogen exposure: Oxidative stress or imbibitional damage. Physiologia Plantarum 119: 534-543.

ELLIS, R. H. (1998): Longevity of seeds stored hermetically at low moisture contents. Seed Sci. Res. 8 (Suppl. 1): 9-10.

Ellis, R. H., T. D. Hong and E. H. RoberTs (1985): Handbook of seed technology for genebanks. Volume I. Principles and Methodology. International Board for Plant Genetic Resources, Rome.

HonG, T. D. and R. H. Ellis (1996): A protocol to determine seed storage behavior. IPGRI Technical Bulletin No. 1. (J. M. M. Engles and J. Toll, vol. eds.). International Plant Genetic Resources Institute, Rome, Italy.

Hor, Y. L., Y. J. Kim, A. UgaP, N. Chabrillange, U. R. Sinniah, F. Engelmann and S. Dussert (2005): Optimal hydration status for cryopreservation of intermediated Oily seeds: Citrus as a case study. Annals of Botany 95: 1153-1161.

IsTA: INTERNATIONAL SEED TESTING ASSOCIATION (1999): International rules for seed testing. Seed Science and Technology 27: 27-32.

IPGRI (2004): In: http://www.ipgri.cigar.org/themes/human/ econmics.htm

KIM, J. D., C. H. Kwon, S. H. CHAw, S. N. HuR and J. G. KIM (2006): Effect of priming materials and its concentrations on the germination of pasture seeds. J. Korean Grass. Sci. 26: 277-284.

KFRI: KOREA FOREST RESEARCH INSTITUTE (2004): Korea rules for forest seed quality testing.

Langis, R., B. Schnabel, E. D. Earle and P. L. Steponkus (1989): Cryopreservation of Brassica campestris L. cell suspensions by vitrification. CryoLetters 10: 421-428.
Lambardi, M., C. Benelli and A. De Carlo (2005): Cryopreservation as a tool for the long-term conservation of woody plant germplasm: Development of the technology at the CNR/IVALSA institute of Florence. The Role of Biotechnology, Villa Gualino, Turin, Italy, 5-7 March, 181-182.

LEUnG, L. K. P. (1991): Principles of biological cryopreservation. In: L. K. P. LeUnG and B. G. M. JAMieson (Eds.), Fish Evolution and Systematics: Evidence from Spermatozoa, Cambridge University Press, New York, 1991.

MicheL, B. E. (1983): Evaluation of the water potentials of solutions of polyethylene glycol 8000 both in the absence and presence of other solutes. Plant Physiology 72: $66-70$.

Oluoch, M. O. and G. E. Welbaum (1996): Effect of post harvest washing and post-storage priming on viability and vigor of sex-year-old muskmelon (Cucumis melo L.) seeds from eight stages of development. Seed Science and Technology 24: 195-209.

PANIS, B. and M. LAMBARDI (2005): Status of cryopreservation technologies in plants (Crops and Forest trees). The Role of Biotechnology, Villa Gualino, Turin, Italy, 5-7 March, 44-54.

PARRY, M. S. (1956): Tree planting practices in tropical Africa. For. Dev. Pap. 8. Rome: FAO. 302p.

PitA, J. M., S. BARRero and A. Escudero (1997): Cryopreservation: an alternative method for the conservation of endangered populations of two Iberian pines (Pinus nigra Arnold and Pinus sylvestris L.). Silvae Genetica 46: $250-253$.

Pita, J. M., V. SANZ and A. Escudero (1998): Seed cryopreservaton of seven Spanish native pine species. Silvae Genetica 47: 220-223.

Probert, R. J., S. V. Bogh, A. J. Smith and G. E. WechsBERG (1991): The effects of priming on seed longevity in Ranunculus sceleratus L. Seed Sci. Res. 1: 243-249.

SAKaI, A., S. KobaYASHI and I. OIYAMA (1990): Cryopreservation of nucellar cells of navel orange (Citrus sinensis Osb. var. brasiliensis Tanaka) by vitrification. Plant Cell Rep. 9: 30-33.

SAITO, M. and H. TAIRA (2005): Plus tree of Cryptomeria japonica D. Don with a heterozygous male-sterility gene. J. For. Res. 10: 391-394.

SAS Institute Inc. (1996): SAS Software Proprietary Release 6.12. Cary (NC): SAS Institute Inc.

SivRITEPE, H. O. and A. M. Dourado (1995): The effect of priming treatments on the viability and accumulation of chromosomal damage in aged pea seeds. Annals of Botany 75: 165-171.

STANWOOD, P. C. (1985): Cryopreservation of seed germplasm for genetic conservation. pp. 199-226. In: Cryopreservation of plant cells and organs edited by K. K. KARTHA. CRC Press, Inc., Boca Ratón, Florida.

STANWOOD, P. C. and S. Sowa (1995): Evaluation of onion (Allium cepa L.) seed after 10 years of storage at $5,-18$, $-196^{\circ} \mathrm{C}$. Crop Science 35: 852-856.

Stofella, P. J., M. Lipucci, D. Paola, A. Pardossi and F. ToGNOMI (1992): Seedling root morphology and shoot growth after seed priming or pregermination of bell pepper. Hort. Science 27: 214-215.

Touchell, D. H. and K. W. Dixon (1993): Cryopreservation of seed of Western Australian native species. Biodiversity and conservation 2: 594-602.

Touchell, D. H. and K. W. Dixon (1994): Cryopreservation for seedbanking of Australian species. Annals of Botany 74: 541-546. 
Uragami, A., A. SAKai, M. NAgAi and T. TAKAhashi (1989): Survival of cultures cells and somatic embryos of Asparagus officinalis L. cryopreserved by vitrification. Plant Cell Rep. 8: 418-421.

Vasquez, N., K. Salazar, F. Anthony, N. Chabrillange, F. Engelmann and S. Dussert (2005): Variability in response of seeds to liquid nitrogen exposure in wild coffee (Coffea arabica L.). Seed Science and Technology 33: 293-301.
VeRTUCCI, C. W. (1989): Relationship between thermal transitions and freezing injury in pea and soybean seeds. Plant Physiology 90: 1121-1128.

WAlters, C., L. WheEler and P. C. StANWOod (2004): Longevity of cryogenically stored seeds. Cryobiology 48: 229-244.

Yousheng, C. and O. SzIKLAI (1985): Preliminary study on the germination of Toona sinensis (A. Juss.) Roem. seed from eleven Chinese provenances. Forest Ecology and Management 10: 269-281.

\title{
Identification and Characterization of Microsatellite Markers Useful for Genetic Analysis of Black Spruce (Picea mariana (Mill.) Populations
}

\author{
By S. Dobrzeniecka ${ }^{1)}$, K. K. Nkongolo ${ }^{\left.1,{ }^{*}\right)}$, P. Michael ${ }^{1)}$, S. Wyss $^{1)}$ and M. Mehes ${ }^{1)}$
}

(Received 28 th April 2008)

\begin{abstract}
Summary
Large - scale isolation of microsatellite and information in any conifer species is limited. Our knowledge of microsatellite in spruce (Picea spp.) is still sketchy. Genomic libraries of $P$. mariana were constructed and screened with $(\mathrm{AC})_{15}$ probes. Over 200 positive clones were found for this dinucleotide and ten were analyzed in details. They were sequenced to confirm the presence of microsatellites and to generate polymerase chain reaction $(\mathrm{PCR})$ primers based on sequences flanking the microsatellites. All sequenced (AC) clones had repeats of $\mathrm{n}>23$. Primer pairs were designed from seven sequences. These primer pairs along with 15 primer pairs from white spruce (Picea glauca) were tested on individual trees. Seven primer pairs from $P$. mariana and three from $P$. glauca (white spruce) amplified DNA from $P$. mariana and were used for genetic analysis of black spruce populations from uplands (drylands) and lowlands (wetlands). High levels of polymorphism and heterozygosity were observed in all the populations studied. Both highlands and lowlands showed similar levels of genetic variation. The selected microsatellites sequences are being used for genome organization analysis of black spruce.
\end{abstract}

Key words: Picea mariana, black spruce, microsatellites, upland, lowland, polymorphism.

\section{Introduction}

Microsatellites (or SSRs) have in recent years become the marker system of choice in population genetics and linkage analysis, due to their co-dominant nature and

\footnotetext{
1) Department of Biology, Laurentian University, Sudbury, Ontario, P3E 2C6, Canada.

*) Corresponding author: K. K. NKONGOLO.

E-Mail: knkongolo@laurentian.ca
}

polymorphism (RAJORA et al., 2001; SCOTTI et al., 2002; GuPTA et al., 2005). The procedures to develop these markers are time - consuming, labour intensive which hinders researchers from isolating such loci (ECHT et al., 1986; EсHT et al., 1996 and ScOTTI et al., 2002).

The relatively low frequency of microsatellites in plant genomes presents some technical problems for largescale isolation of microsatellites and information in any particular plant species is limiting. This problem can be overcome by using previously developed microsatellite primers from related species due to the conservation of the flanking sequence (EcHT et al., 1999). This would reduce development costs and provide useful information for comparative linkage relationships between species (EcHT, 1999). To date, there are no reported studies of genetic diversity in Picea mariana (black spruce) populations using microsatellite markers. A limited number of microsatellite DNA markers have been developed for few spruce species, Norway spruce (Picea abies), Sitka spruce (P. sitechensis), and white spruce (P. glauca) (HodGeTts et al., 2001; PFEIFFER et al., 1997; ScOTTI et al., 2002; and RAJORA et al., 2001). The main objective of the present study was to develop and characterize microsatellite primers from $P$. mariana genomic DNA libraries. These $P$. mariana derived primers along with heterologous primers from $P$. glauca were used to characterize populations growing in different ecological areas, mainly uplands (drylands) and lowlands (wetlands)

\section{Material and Methods}

\section{Genetic materials}

For the library construction, black spruce needles were collected from individual trees from Petawawa for- 